\title{
A clinical study of the effects of cilnidipine and amlodipine in hypertensive patient focusing on pedal edema
}

\author{
Uniyal $\mathbf{N}^{1}$, Singh $\mathbf{V}^{2}$ \\ ${ }^{1}$ Dr. Nidhi Uniyal, Assistant Professor; ${ }^{2}$ Dr Vikaram Singh, Associate Professor, both authors are affiliated with \\ Department of Medicine, Government, Doon Medical College, Dehradun, UK, India.
}

Address for Correspondence: Dr. Nidhi Uniyal, E-mail: nitinkbansal18@ gmail.com

\begin{abstract}
Introduction: Many Calcium channel blocker drugs for control of hypertension are available. New drug Cilinidipine is available and approved for treatment of hypertension. It acts by blocking both L-type and N-type voltage-dependent calcium channels. The neural N-type blockade leads to stoppage of the secretion of norepinephrine and it also depresses sympathetic nervous system activity. The aim of the study is to assess the effect of cilnidipine and amlodipine on hypertensive patient. Method: Clinidipine $(n=50)$ and Amolodipine $(n=50)$ were given once daily and BP was measured daily before and after the medicine in 100 hypertensive patients on OPD basis in GDMC, Dehradun. Result: Only 4 patients $(n=50 ; 8 \%)$ in cilnidipine group developed edema within 10 days of therapy, while 32 patients $(n=50,64 \%)$ developed with edema within 10 days of treatment in amlodipine group. Conclusion: Cilnidipine is also associated with less incidences of pedal edema which is main complaint of patient. It controls BP better with less reflex tachycardia and decrease in morning surge.
\end{abstract}

Key words: Cilnidipine, BP, Calcium antagonists.

\section{Introduction}

BP control reduces the target organ damage and improves the clinical outcome in patients with hypertension [1-6]. In Japan calcium antagonists (Amlodipine) have been widely used for the treatment of hypertension [7, 8]. Short-acting calcium channel blocker causes sympathetic activity and reflex tachycardia while Amlodipine because of its long duration of action avoids [9]. Amlodipine controls BP levels throughout a 24-h period $[10,11]$.

Cilnidipine is a new drug of Calcium Channel blocker group and blocks both L-typeand N-type voltagedependent calcium channels [12]. The N-type voltagedependent calcium channel regulates the release of norepinephrine from sympathetic nerve endings [13]. Once-daily administration of cilnidipine results in BP decrease without reflex tachycardia than similar administration than once-daily administration of nifedipine $[14,15]$. The morning rise in BP increases the

Manuscript received $5^{\text {th }}$ July 2016

Reviewed: $20^{\text {th }}$ July 2016

Author Corrected: $4^{\text {th }}$ August 2016

Accepted for Publication $17^{\text {th }}$ August 2016 risk of stroke independent of age and 24-h BP level in hypertensive patients significantly [16]. Amlodipine due to its long duration of action, controls 24-BP and it is associated with morning rise which is useful for the prevention of cardiovascular events in hypertensive patients. Sympathetic nervous activity is high in the morning, and may contribute to morning BP surge [17], and cilnidipine, due to N-type calcium channel blockade, causes morning rise BP.

Cilnidipine and Amlodipine have clinical benefits resulting from the unique characteristics of each agent. We compared the effects of cilnidipine and amlodipine on ambulatory $\mathrm{BP}$ and pulse rate (PR) monitoring in patients $(n=100)$ with essential hypertension.

\section{Methods}

We correlated by an open-label, randomized study of the effects of once-daily morning administration of cilnidipine and amlodipine on ambulatory BP. 100 hypertensive outpatients with systolic BP (SBP) $\geq 140$ $\mathrm{mmHg}$ or diastolic BP (DBP) $\geq 90 \mathrm{mmHg}$ on two or 
more occasions were included in the study. The studied patients were randomly selected from outpatients who met the following criteria. No antihypertensive patients received medication for last one month before the start of the study.

The physical examination was done and blood and urine tests, chest X-ray, and a resting electrocardiogram, were done and were normal. Renal and liver function was normal. There was no patient having history of coronary artery disease, stroke (including transient ischemic attack), congestive heart failure, or malignancy. All patients were well informed and consent was taken from all of the subjects.
Approval from Ethical Committee was taken. One hundred and ten patients were studies for this study.

$10 \mathrm{mg}$ once a day clilnidipine was given orally for one month. Amlodipine $5 \mathrm{mg}$ was given orally once daily for 4 weeks. We do not increase the dosage of amlodipine and clinidipine. Each patient was studied for 16 weeks.

The BP was monitored by LCD BP instrument 8.00 AM and $8.00 \mathrm{PM}$ before starting of treatment and then at 16 week. Morning BP was defined as the mean BP during the first $2 \mathrm{~h}$ after awakening.

\section{Results}

Total 100 patients included and completed the study. Patient's age for amlodipine group ranged between 30 to 60 years and 32 to 64 cilnidipine group [Table 1]. Women $(n=28)$ were more than men $(n=22)$ in both the study groups. Both the groups were compared.

Table-1: Distribution of patients.

\begin{tabular}{|c|c|c|c|}
\hline Patients & Amlodipine & Cilinidipine & Total \\
\hline Number & 50 & 50 & $31-62$ \\
\hline Age (Years) range & $30-60$ & $32-64$ & 44 \\
Gender & 22 & 22 & 56 \\
Fale & 28 & 28 & \\
\hline
\end{tabular}

SBP and DBP $(P<0.05)$ reduction was appropriate in both groups compared to baseline data [Table 2]. Efficacy in both group was similar $(P>0.05)$.

Table-2: Variation in blood pressure after treatment.

\begin{tabular}{|c|c|c|c|c|c|}
\hline BP & Treatment & $\begin{array}{c}\text { Pre-treatment } \\
\text { BP }\end{array}$ & $\begin{array}{c}\text { Post-treatment } \\
\text { BP }\end{array}$ & difference & p - value \\
\hline SBP & $\begin{array}{l}\text { Amlodipine } \\
\text { Cilnidipine }\end{array}$ & $\begin{array}{l}166 \pm 8 \\
168 \pm 8\end{array}$ & $\begin{array}{c}140 \pm 10 \\
142 \pm 6\end{array}$ & $\begin{array}{l}26 \pm 9.0 \\
26 \pm 7.0\end{array}$ & $\begin{array}{l}<0.001 \\
<0.001\end{array}$ \\
\hline DBP & $\begin{array}{l}\text { Amlodipine } \\
\text { Cilnidipine }\end{array}$ & $\begin{array}{c}94 \pm 10 \\
98 \pm 7\end{array}$ & $\begin{array}{l}80 \pm 6 \\
84 \pm 6\end{array}$ & $\begin{array}{l}14 \pm 4.0 \\
14 \pm 1.0\end{array}$ & $\begin{array}{l}<0.001 \\
<0.001\end{array}$ \\
\hline
\end{tabular}

Only 4 patients $(n=50 ; 8 \%)$ in cilnidipine group developed edema within 10 of therapy, while 32 patients $(n=50$, 64\%) developed with edema within 10 days of treatment in amlodipine group (Table 3).

Cilnidipine has shown significant reduction in the incidence of pedal edema when compared to amlodipine $(P<0.05)$.

There were no other significant adverse reactions observed in either amlodipine or cilnidipine group (other than pedal edema). 
Table-3: Edema in both group.

\begin{tabular}{|c|c|c|c|c|}
\hline Drug & Edema (\%) & $\begin{array}{c}\text { Without edema } \\
(\boldsymbol{\%})\end{array}$ & Total & p-value \\
\hline Amlodipine & $32(64 \%)$ & $18(36 \%)$ & 50 & $<0.001$ \\
\hline Cilnidipine & $4(8 \%)$ & $46(92 \%)$ & 50 & $<0.001$ \\
\hline Total & $\mathbf{3 6 ( 3 6 \% )}$ & $\mathbf{6 4}(\mathbf{6 4 \% )}$ & $\mathbf{1 0 0}$ & \\
\hline
\end{tabular}

Statistical analysis- Antihypertensive efficacy between two groups was compared by unpaired $t$-test.

\section{Discussion}

Cilnidipine or amlodipine are used in treatment of hypertension and reduce the ambulatory $\mathrm{BP}$ and morning BP. Cilnidipine, does not increase in pulse rate $[18,19]$. Cilnidipine causes significantly decrease in Pulse Rate than amlodipine treatment in hypertensive patients. It is well documented that a higher heart rate is associated with a long-term risk of cardiovascular mortality, independent of other cardiac risk factors [20]. Therefore, antihypertensive drugs not causing tachycardia are preferred drug of treatment of hypertension. It has been reported that treatment with short-acting calcium antagonists may not prevent cardiovascular disease [21, 22].

Gradual BP reduction is desirable and rapid fall in BP and an increase in sympathetic activity have been suggested as possible underlying mechanisms for this unexpected outcome [23]. Long acting calcium channel blockers that exert less influence on the sympathetic activity are now recommended for treatment of hypertension [24].

The long-acting nature of amlodipine (which has a halflife of $45 \mathrm{~h}$ after a single oral dose [25], leads to a reduction of BP throughout the day and night [10], and prevents an increase in sympathetic activity [26]. In our study, increase in PR by amlodipine was significant.

Recently, some studies have reported that amlodipine increased PR, sympathetic activity, and reflex tachycardia via a reduction in $\mathrm{BP}$, which are common adverse effects of conventional dihydropyridine calcium antagonists [27, 28]. Changes of PR is dose dependent.

Lowering of BP was associated with a significant fall in cardiovascular events [29]. Therefore, in hypertensive treatment, it is not clear whether the reduction of PR is more effective in the prevention of cardiovascular events than the reduction of $\mathrm{BP}$.
Cilnidipine is also a long-acting dihydropyridine calcium antagonist and it is associated with reduction of pulse rate along with significant reduction of BP. Both amlodipine and cilnidipine have been applied clinically based on their ability to blockade both the L-type and N-type calcium channels [18]. Cilnidipine is significantly more selective in blocking the N-type calcium channel than other calcium antagonists $[14,15$, 18, 19, 26, 31, and 32]. Blockade of the neural N-type calcium channel inhibits the secretion of norepinephrine from peripheral neural terminals [12]. As sympathetic

activity is not increased by blocking the $\mathrm{N}$-type calcium channels with cilnidipine, it may be the cause a decrease in PR. Clinically, Sakata et al. demonstrated by using 123I-metaiodobenzylguanidine cardiac imaging that cilnidipine suppressed cardiac sympathetic overactivity while amlodipine had little suppressive effect [18].

In this study, we could not prove this hypothesis because we did not measure an index of sympathetic nervous activity in our study. Morning BP surge were associated with target organ damage [33] and stroke events in hypertensive patients [16]. The treatment of morning BP is very important. Whereas arousal from sleep is associated with a slight rise in plasma epinephrine, arising induces a significant rise in both epinephrine and norepinephrine. We speculated that cilnidipine therapy with its sympathetic inhibitory action was more effective than amlodipine therapy in controlling morning BP in hypertensive patients.

Generally speaking, there have been problems with the reproducibility of ABPM. Nonetheless, some reports have shown that ABPM was useful for evaluating the BP-lowering effects of antihypertensive drugs. In conclusion, N-type calcium channel blockade by 
cilnidipine may not cause reflex tachycardia, and may be useful for hypertensive treatment.

\section{Conclusion}

Cilnidipine is also associated with less incidences of pedal edema which is main complaint of patient. It controls BP better with less reflex tachycardia and decrease in morning surge. Thus, Cilnidipine is better antihypertensive drug than amlodipine.

Funding: Nil, Conflict of interest: None initiated, Permission from IRB: Yes

\section{References}

1. Fukuo K, Yang J, Suzuki T, et al: Nifedipine upregulates manganese superoxide dismutase expression in vascular smooth muscle cells via endothelial cell-dependent pathways. Hypertens Res 2003; 26: 503-508.

2. Yao K, Sato H, Sonoda R, Ina Y, Suzuki K, Ohno T. Effects of benidipine and candesartan on kidney and vascular function in hypertensive Dahl rats. Hypertens Res. 2003 Jul;26(7):569-76.

3. Umemoto S, Tanaka M, Kawahara S, et al: Calcium antagonist reduces oxidative stress by upregulating $\mathrm{Cu} / \mathrm{Zn}$ superoxide dismutase in stroke- prone spontaneously hypertensive rats. Hypertens Res 2004; 27: $877-885$.

4. Yamagata K, Ichinose S, Tagami M. Amlodipine and carvedilol prevent cytotoxicity in cortical neurons isolated from stroke-prone spontaneously hypertensive rats. Hypertens Res. 2004 Apr;27(4):271-82.

5. Yui Y, Sumiyoshi T, Kodama K, Hirayama A, Nonogi H, Kanmatsuse K, Origasa H, Iimura O, Ishii M, Saruta T, Arakawa K, Hosoda S, Kawai C; Japan Multicenter Investigation for Cardiovascular DiseasesB Study Group. Comparison of nifedipine retard with angiotensin converting enzyme inhibitors in Japanese hypertensive patients with coronary artery disease: the Japan Multicenter Investigation for Cardiovascular Diseases-B (JMIC-B) randomized trial. Hypertens Res. 2004 Mar;27(3):181-91.

6. Yui Y, Sumiyoshi T, Kodama K, et al: Nifedipine retard was as effective as angiotensin converting enzyme inhibitors in preventing cardiac events in highrisk hypertensive patients with diabetes and coronary artery disease: the Japan Multicenter Investigation for Cardiovascular Diseases-B (JMIC-B) subgroup analysis. Hypertens Res 2004; 27: 449- 456.

7. Saruta T. Current status of calcium antagonists in Japan. Am J Cardiol. 1998 Nov 12; 82 (9B) : 32R34R.

8. Hirose H, Saito I. Trends in blood pressure control in hypertensive patients with diabetes mellitus in Japan. Hypertens Res. 2003 Sep;26(9):717-22.

9. Grossman E, Messerli FH. Effect of calcium antagonists on sympathetic activity. Eur Heart J. 1998 Jun;19 Suppl F:F27-31.

10. Kario K, Shimada K: Differential effects of amlodipine on ambulatory blood pressure in elderly hypertensive patients with different nocturnal reductions in blood pressure. Am J Hypertens 1997; 10: 261-268.

11. Kuramoto K, Ichikawa S, Hirai A, Kanada S, Nakachi T, Ogihara T. Azelnidipine and amlodipine: a comparison of their pharmacokinetics and effects on ambulatory blood pressure. Hypertens Res. 2003 Mar; 26(3):201-8.

12. Fujii S, Kameyama K, Hosono M, Hayashi Y, Kitamura K. Effect of cilnidipine, a novel dihydropyridine $\mathrm{Ca}++-$ channel antagonist, on N-type $\mathrm{Ca}++$ channel in rat dorsal root ganglion neurons. J Pharmacol Exp Ther. 1997 Mar;280(3):1184-91.

13. Hirning LD, Fox AP, McCleskey EW, Olivera BM, Thayer SA, Miller RJ, Tsien RW. Dominant role of Ntype $\mathrm{Ca} 2+$ channels in evoked release of norepinephrine from sympathetic neurons. Science. 1988 Jan 1; 239 (4835):57-61.

14. Minami J, Ishimitsu T, Kawano $Y$, Numabe A, Matsuoka H. Comparison of 24-hour blood pressure, heart rate, and autonomic nerve activity in hypertensive patients treated with cilnidipine or nifedipine retard. J Cardiovasc Pharmacol. 1998 Aug; 32 (2): 331-6.

15. Minami J, Ishimitsu $\mathrm{T}$, Higashi $\mathrm{T}$, Numabe $\mathrm{A}$, Matsuoka H: Comparison between cilnidipine and nisoldipine with respect to effects on blood pressure and heart rate in hypertensive patients. Hypertens Res 1998; 21: 215-219. 
16. Kario K, Pickering TG, Umeda $\mathrm{Y}$, Hoshide $\mathrm{S}$, Hoshide Y, Morinari M, Murata M, Kuroda T, Schwartz JE, Shimada K. Morning surge in blood pressure as a predictor of silent and clinical cerebrovascular disease in elderly hypertensives: a prospective study. Circulation. 2003 Mar 18; 107 (10):1401-6.

17. Panza JA, Epstein SE, Quyyumi AA. Circadian variation in vascular tone and its relation to alphasympathetic vasoconstrictor activity. N Engl J Med. 1991 Oct 3;325(14):986-90.

18. Sakata K, Shirotani M, Yoshida H, et al: Effects of amlodipine and cilnidipine on cardiac sympathetic nervous system and neurohormonal status in essential hypertension. Hypertension 1999; 33: 14471452.

19. Tomiyama H, Kimura Y, Kuwabara Y, et al: Cilnidipine more highly attenuates cold pressor stressinduced platelet activation in hypertension than does amlodipine. Hypertens Res 2001; 24: 679684 .

20. Gillman MW, Kannel WB, Belanger A, D'Agostino $\mathrm{RB}$. Influence of heart rate on mortality among persons with hypertension: the Framingham Study. Am Heart J. 1993 Apr;125(4):1148-54.

21. Furberg CD, Psaty BM, Meyer JV. Nifedipine. Dose-related increase in mortality in patients with coronary heart disease. Circulation. 1995 Sep 1;92 (5):1326-31.

22. Psaty BM, Heckbert SR, Koepsell TD, Siscovick DS, Raghunathan TE, Weiss NS, Rosendaal FR, Lemaitre RN, Smith NL, Wahl PW, et al. The risk of myocardial infarction associated with antihypertensive drug therapies. JAMA. 1995 Aug 23-30; 274 (8): $620-5$.

23. Ruzicka M, Leenen FH. Relevance of $24 \mathrm{H}$ blood pressure profile and sympathetic activity for outcome on short- versus long-acting 1,4-dihydropyridines. Am J Hypertens. 1996 Jan;9(1):86-94.

24. Chobanian AV, Bakris GL, Black HR, et al: The seventh report of the Joint National Committee on Prevention, Detection, Evaluation, and Treatment of High Blood Pressure: the JNC 7 report. JAMA 2003; 289: 2560-2571.
25. Faulkner JK, McGibney D, Chasseaud LF, Perry JL, Taylor IW: The pharmacokinetics of amlodipine in healthy volunteers after single intravenous and oral doses and after 14 repeated oral doses given once daily. Br J Clin Pharmacol 1986; 22: 21-25.

26. Minami J, Ishimitsu T, Kawano Y, Matsuoka H. Effects of amlodipine and nifedipine retard on autonomic nerve activity in hypertensive patients. Clin Exp Pharmacol Physiol. 1998 Jul-Aug; 25(7-8): 572-6.

27. Lefrandt JD, Heitmann J, Sevre K, et al: The effects of dihydropyridine and phenylalkylamine calcium antagonist classes on autonomic function in hypertension: the VAMPHYRE study. Am J Hypertens 2001; 14: 1083-1089.

28. Struck J, Muck P, Trubger D, et al: Effects of selective angiotensin II receptor blockade on sympathetic nerve activity in primary hypertensive subjects. J Hypertens 2002; 20: 1143-1149.

29. ALLHAT Officers and Coordinators for the ALLHAT Collaborative Research Group: Major outcomes in high-risk hypertensive patients randomized to angiotensin-converting enzyme inhibitor or calcium channel blocker vs diuretic: the Antihypertensive and Lipid-Lowering Treatment to Prevent Heart Attack Trial (ALLHAT). JAMA 2002; 288: 2981- 2997.

30. Ishii M, Kakuo M, Shishido R, Okuno T, Itida S, Matsumoto M: Phase 1 clinical study of FRC-8635 (cilnidipine): single-dose study. Jpn Pharmacol Ther 1993; 21 (Suppl 1): S7-S22.

31. Morimoto S, Takeda K, Oguni A, Kido H, Harada S, Moriguchi J, Itoh H, Nakata T, Sasaki S, Nakagawa M. Reduction of white coat effect by cilnidipine in essential hypertension. Am J Hypertens. 2001 Oct; 14 (10):1053-7.

32. Kojima S, Shida M, Yokoyama H: Comparison between cilnidipine and amlodipine besilate with respect to proteinuria in hypertensive patients with renal diseases. Hypertens Res 2004; 27: 379-385.

33. Ikeda T, Gomi T, Shibuya Y, et al: Morning rise in blood pressure is a predictor of left ventricular hypertrophy in treated hypertensive patients. Hypertens Res 2004; 27: 939- 946. 


\section{How to cite this article?}

Uniyal N, Singh V. A clinical study of the effects of cilnidipine and amlodipine in hypertensive patient focusing on pedal edema. Int J Med Res Rev 2016;4(8):1502-1507.doi:10.17511/ijmrr.2016.i08.34. 